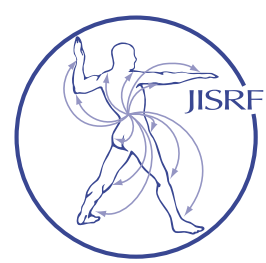

\title{
Can We Improve Screening Costs in Asymptomatic Metal on Metal Total Hip Arthroplasties?
}

Martin $J R^{1}$, Otero $J E^{2}$, Springer $B D^{1}$, Griffin $W L^{1}$

\section{Abstract}

Background: Metal on Metal (MoM) total hip arthroplasty (THA) has been largely abandoned in the United States secondary to high failure rates. Many of the failures are attributed to adverse local tissue reactions (ALTR). Therefore, patients that have a MoM THA are routinely screened by checking serum metal ion levels every two years, as was recommended by the FDA. However, there is limited data on the costs of current screening protocols.

Materials and Methods: 318 consecutive patients who underwent a MoM THA at a single institution were retrospectively enrolled. The average follow-up was 8.2 years. Clinical data, metal ion levels, revision and reoperation rates were prospectively collected. The costs of clinical screening for this patient population was calculated and compared to the cost of an annual screening protocol.

Results: 12 patients had either an elevated $\mathrm{Co}$ or $\mathrm{Cr}$ level ( $>4.5 \mathrm{ppb})$. Eight patients were revised secondary to ALTR. The total cost of screening during the study was $\$ 612,250$. Additionally, if annual screening had been performed, total screening costs would be approximately $\$ 1,719,200$.

Discussion: Eight patients in the following study were revised secondary to ALTR with a total cost of screening of $\$ 612,500$. These costs are substantially less than the cost of annual screening $(\$ 1,719,200)$. Due to the considerable costs of screening asymptomatic MoM THA patients, we recommend both optimizing the frequency of screen- ing and evaluating the specific risk of the implant being screened.

\section{Background}

Metal on metal (MoM) total hip arthroplasty (THA) has largely been abandoned as a bearing surface as numerous studies have demonstrated adverse local tissue reactions secondary to the implant bearing [1-4]. The exact number of patients implanted with a MoM THA has been estimated to be over $1,000,000$. It is believed that there remain hundreds of thousands of asymptomatic patients with these implants that still require follow-up. There is currently no consensus on how to screen this patient population to avoid complications associated with adverse local tissue reaction $[\underline{5}, 6]$. Some international screening protocols require annual follow-up with serum or whole blood cobalt and chromium metal ion levels. "Elevated" levels (which may range from 4.5 to $7.5 \mathrm{ppb}$ ) commonly require cross sectional imaging including a Metal Artifact Reduction Sequence Magnetic Resonance Imaging (MARS MRI) or an ultrasound [7-9].

Metal ion values have not demonstrated a clear relation-

Keywords: metal on metal; total hip replacements; screening protocols; cost savings

Level of Evidence: AAOS Therapeutic Level IV 
ship in the diagnosis of adverse local tissue reaction [10]. The actual metal ion value that is considered "elevated" varies, and may not directly correlate with adverse local tissue reaction $[11,12]$. Additionally, the timing for obtaining metal ion levels and the time interval between screenings is not uniform. In the United Kingdom, the Medicines and Healthcare products Regulatory Agency (MHRA) currently recommends annual screening for all patients with a MoM THA with a femoral head $36 \mathrm{~mm}$ or larger [13]. However, Kiran et. al. noted that metal ion levels remained stable after seven years and had no significant elevation. Therefore, they suggested that annual screening may not be necessary [12]. Additionally, there is a paucity of data available on the costs of screening this patient population.

Beginning in 2010, we adopted a protocol of monitoring metal ion levels every two years in asymptomatic MoM THA patients. Prior to this, routine screening was not utilized for asymptomatic patients. Revision THA secondary to adverse local tissue reaction has been minimal at our institution; therefore, there remains a substantial cost for screening this asymptomatic patient population. Consequently, the following study was designed to determine the costs of our current surveillance program on asymptomatic MoM THA patients and to compare these with the potential costs of annual screening. Additionally, we sought to determine the cost per patient to identify a single case of an adverse local tissue reaction.

\section{Materials and Methods}

After obtaining institutional review board approval, the following study was performed retrospectively. 318 consecutive patients underwent primary THA. All THAs were performed by the senior author, a fellowship trained arthroplasty surgeon, through a posterior approach. A Pinnacle (DePuy; Warsaw, IN) acetabular component with an Ultamet metal liner was utilized in each case. $98 \%$ of cases were performed with the S-ROM stem (DePuy; Warsaw, IN) and 2\% were performed with an AML stem (DePuy; Warsaw, IN).

\section{Patient Demographics}

The patient cohort included 318 patients with $457 \mathrm{MoM}$ THAs identified. The average age at the time of surgery was 55 years (20-78 years). The average time in situ was $8.2 \mathrm{yrs}$. The median femoral head size was $36 \mathrm{~mm}$ and the median cup angle was 40 degrees.

\section{Screening Protocol}

Routine monitoring for patients with asymptomatic
MoM THA included a physical examination, AP pelvis and lateral radiograph of the involved hip, and cobalt and chromium metal ion levels. However, there was not a standardized time between physical examination/screens. Starting in 2010, patients were routinely screened every two years. The screening period coincided with the widespread availability of cobalt and chromium metal ion labs. Prior to this time, only a few centers had the ability to measure serum/ whole blood metal ion levels. Sidaginamale et. al. [15] previously noted that a Co level of $4.5 \mathrm{ppb}$ was highly sensitive and specific for the detection of abnormal wear of a MoM THA. While other cutoff values have been evaluated, we chose $4.5 \mathrm{ppb}$ as a more sensitive screening level. Therefore, any metal ion level over $4.5 \mathrm{ppb}$ was considered elevated by the senior author and the patient was then scheduled to undergo a MARS MRI. Fluid collections suggestive of adverse local tissue reaction in the setting of elevated metal ions were considered to be diagnostic for a failed metal on metal total hip arthroplasty and were subsequently revised. Therefore, we calculated the costs of screening based on 1) actual follow-up, 2) desired followup (every 2-years), 3) annual follow-up, and 4) every fouryears with the assumption that the same number of ALTR were identified in each screening protocol. A multivariate analysis was performed on our patient population to determine if any patient demographics were associated with an increased risk of ALTR.

\section{Costs of Screening}

Costs of screening metal ion levels are not uniform and have changed throughout the duration of the study. The costs as of 2014 were approximately $\$ 300$, but have decreased to around $\$ 124$ as of 2018 for one laboratory. It should be noted that screening evaluations will likely continue to become more cost-effective with decreasing lab costs. However, in order to simplify the calculations, the costs of each screening modality are approximated. The table below demonstrates the approximate costs for each exam/test (Table 1).

Table 1

\begin{tabular}{|l|l|}
\hline Exam/Test & Cost of Exam (dollars) \\
\hline Clinical Exam/X-rays & 350 \\
\hline Metal Ion Levels & 300 \\
\hline MARS MRI & 2000 \\
\hline
\end{tabular}

Patients were followed with serial clinical examination, $\mathrm{x}$-rays, and metal ion levels. If an elevated metal ion level was identified, the patient underwent a MARS MRI. All patients that had a positive MRI (large fluid collections, soft tissue masses, etc.) and a clinical examination 
concerning for mechanical symptoms or increasing pain underwent revision for ALTR. The total costs of routine screening as well as MRI evaluation for those with elevated metal ion levels were calculated for this patient population. Additionally, the theoretical screening costs were then calculated utilizing both planned screening as well as annual serial screening protocols. It was assumed that the same number of elevated metal ion levels would be identified as well as the same number of ALTR.

\section{Results}

We identified 18 elevated cobalt and or chromium levels in 12 patients of the 318 (3.8\%). The median cobalt and chromium level on lab draw one was $1.3 \mathrm{ppb}$ and $1.1 \mathrm{ppb}$ and on lab draw 2 was $1.4 \mathrm{ppb}$ and $1.3 \mathrm{ppb}$, respectively. Of the 12 patients that underwent MARS MRI for elevated metal ion levels, eight patients $(2.5 \%)$ had confirmed cases of ALTR and were subsequently revised. Of these eight patients, two had groin pain concerning for an ALTR, one patient had radiating low back pain, and the other five patients were minimally symptomatic. The only risk factor associated with ALTR was the time in situ ( $\mathrm{p}=0.0008)$. Age, gender, cup abduction angle, and femoral head size were not statistically associated with an increased risk of ALTR.

\section{Total Cost of Current Screening}

The costs for the clinical evaluations and $\mathrm{x}$-rays for this cohort was $\$ 316,750$. The cost of screening patients with metal ion levels was $\$ 271,500$. The costs of the MARS MRIs on 12 patients were approximately $\$ 24,000$. Therefore, the total cost of screening for this study was $\$ 612,250$ (Table 2). The cost therefore was $\$ 1,925$ per patient.

Table 2

\begin{tabular}{|l|l|l|l|}
\hline Exam/Test & $\begin{array}{l}\text { Number of } \\
\text { Exams (n) }\end{array}$ & $\begin{array}{l}\text { Cost per exam } \\
\text { (dollars) }\end{array}$ & $\begin{array}{l}\text { Total cost } \\
\text { (dollars) }\end{array}$ \\
\hline $\begin{array}{l}\text { Clinical } \\
\text { Exam/X-rays }\end{array}$ & 905 & 350 & 316,750 \\
\hline $\begin{array}{l}\text { Metal Ion } \\
\text { Levels }\end{array}$ & 905 & 300 & 271,500 \\
\hline MARS MRI & 12 & 2000 & 24,000 \\
\hline Total & & & 612,250 \\
\hline
\end{tabular}

\section{Cost per ALTR}

Eight patients in this study were revised secondary to an ALTR which was confirmed on the pre-operative MARS MRI and intraoperatively. Therefore, our current screening protocol has a cost of $\$ 76,531$ per ALTR identified.

\section{Costs of Planned Screening Protocol (every two years)}

Utilizing the planned screening protocol every two years, the cost of clinical exams and x-rays would be $\$ 456,750$. The cost of screening the entire cohort of patients with metal ion levels would be $\$ 391,200$. The costs of the MRI evaluations would also be $\$ 24,000$. The total costs of screening utilizing this protocol would be $\$ 871,950$, or $\$ 2,742$ per patient. Additionally, the cost of this theoretical screening protocol would be approximately $\$ 108,994$ per ALTR (Table 3).

Table 3

\begin{tabular}{|l|l|l|l|}
\hline Exam/Test & $\begin{array}{l}\text { Number of } \\
\text { Exams (n) }\end{array}$ & $\begin{array}{l}\text { Cost per exam } \\
\text { (dollars) }\end{array}$ & $\begin{array}{l}\text { Total cost } \\
\text { (dollars) }\end{array}$ \\
\hline $\begin{array}{l}\text { Clinical Exam/ } \\
\text { X-rays }\end{array}$ & 1304 & 350 & 456,750 \\
\hline $\begin{array}{l}\text { Metal Ion } \\
\text { Levels }\end{array}$ & 1304 & 300 & 391,200 \\
\hline MARS MRI & 12 & 2000 & 24,000 \\
\hline Total & & & 871,950 \\
\hline
\end{tabular}

\section{Costs of Theoretical Screening Protocol (annual)}

Utilizing an annual screening protocol, the cost of clinical exams and x-rays would be $\$ 912,800$. The cost of screening the entire cohort of patients with metal ion levels would be $\$ 782,400$. The costs of the MRI evaluations would also be $\$ 24,000$. The total costs of screening utilizing this protocol would be $\$ 1,719,200$, or $\$ 5,406$ per patient. Additionally, the cost of this theoretical screening protocol would be approximately $\$ 214,900$ per ALTR (Table 4).

Table 4
\begin{tabular}{|l|l|l|l|}
\hline Exam/Test & $\begin{array}{l}\text { Number of } \\
\text { Exams (n) }\end{array}$ & $\begin{array}{l}\text { Cost per exam } \\
\text { (dollars) }\end{array}$ & $\begin{array}{l}\text { Total cost } \\
\text { (dollars) }\end{array}$ \\
\hline $\begin{array}{l}\text { Clinical Exam/ } \\
\text { X-rays }\end{array}$ & 2608 & 350 & 912,800 \\
\hline $\begin{array}{l}\text { Metal Ion } \\
\text { Levels }\end{array}$ & 2608 & 300 & 782,400 \\
\hline MARS MRI & 12 & 2000 & 24,000 \\
\hline Total & & & $1,719,200$ \\
\hline
\end{tabular}

\section{Comparison of Theoretical Screening Protocol (four- years)}

Utilizing a protocol to screen every four-years, the cost of clinical exams and $x$-rays would be $\$ 228,200$. The cost of screening the entire cohort of patients with metal ion levels would be $\$ 195,600$. The costs of the MRI evaluations would also be $\$ 24,000$. The total costs of screening utilizing this protocol would be $\$ 447,800$, or $\$ 1,408$ per patient. Additionally, the cost of this theoretical screening 
protocol would be approximately $\$ 55,975$ per ALTR (Table 5). The following table compares the screening costs amongst the various durations of screening (Table 6).

Table 5

\begin{tabular}{|l|l|l|l|}
\hline Exam/Test & $\begin{array}{l}\text { Number of } \\
\text { Exams (n) }\end{array}$ & $\begin{array}{l}\text { Cost per exam } \\
(\text { dollars })\end{array}$ & $\begin{array}{l}\text { Total cost } \\
(\text { dollars })\end{array}$ \\
\hline $\begin{array}{l}\text { Clinical Exam/ } \\
\text { X-rays }\end{array}$ & 652 & 350 & 228,200 \\
\hline $\begin{array}{l}\text { Metal Ion } \\
\text { Levels }\end{array}$ & 652 & 300 & 195,600 \\
\hline MARS MRI & 12 & 2000 & 24,000 \\
\hline Total & & & 447,800 \\
\hline
\end{tabular}

Table 6

\begin{tabular}{|l|l|l|l|l|}
\hline Protocol & $\begin{array}{l}\text { Current } \\
\text { Screening }\end{array}$ & Annual & $\begin{array}{l}\text { Two- } \\
\text { years }\end{array}$ & $\begin{array}{l}\text { Four- } \\
\text { years }\end{array}$ \\
\hline $\begin{array}{l}\text { Total Costs } \\
\text { (dollars) }\end{array}$ & 612,250 & $1,719,200$ & 871,950 & 447,800 \\
\hline $\begin{array}{l}\text { Costs/Patient } \\
\text { (dollars) }\end{array}$ & 1,925 & 5,406 & 2,742 & 1,408 \\
\hline $\begin{array}{l}\text { Costs/100 Patients } \\
\text { (dollars) }\end{array}$ & 192,500 & 540,600 & 274,200 & 140,800 \\
\hline
\end{tabular}

\section{Discussion}

Current screening protocols for monitoring patients with metal on metal total hip arthroplasties are not uniform $[\underline{14}, \underline{16}-\underline{18}]$. In the United Kingdom, annual screenings with metal ion levels are required. However, in the United States, starting in 2010 the FDA mandated ion level screening every two years for asymptomatic MoM THA. This mandate is no longer required but is still generally followed. One recent study has demonstrated that metal ion levels appear to remain stable over time and annual metal ion levels are likely not necessary [14]. This led us to reevaluate our current screening process. There is a substantial cost for screening patients, and more frequent screens will continue to increase costs. However, to our knowledge, no study has evaluated the costs of screening protocols in asymptomatic patients with MoM THA. Therefore, the following study was designed to evaluate theoretical and actual costs of screening this patient population.

Utilizing a less stringent screening protocol than what the MHRA recommends in the UK (screening every year), we identified a total cost of screening for this study of $\$ 612,250$ over an 8.2 year time period. These screening costs are relatively high. However, these costs are substantially less than what may be observed with annual screening protocols. Our results demonstrate an approximately three-fold increase in the costs of screening utilizing annual protocols. As was previously discussed and demonstrated in our study, metal ion levels appear to remain fairly constant with repeat lab evaluation [14]. It should be noted that the true incidence of ALTR was not known in our study. We have made the assumption that all cases of ALTR were identified with the current screening protocol. While it is intuitive that more frequent screening would lead to increasing costs, it is not certain if more frequent screening will identify more patients with an ALTR. MARS MRI has been noted to identify fluid collections in well-functioning ceramic on polyethylene and metal on polyethylene THAs $[\underline{19}, \underline{20}]$. The two main screening tools for identifying an ALTR (metal ion levels and MARS MRI) do not necessarily confirm the diagnosis of ALTR. Therefore, there does not appear to be a nonsurgical method for defining the true incidence of ALTR.

As was demonstrated in this study, screening asymptomatic MoM THA patients is expensive. Further research is necessary to more accurately define at risk patients for an ALTR. In this study, all patients were implanted with the Pinnacle MoM acetabular component. This implant has been associated with statistically significantly lower metal ion levels than other MoM implant designs [21]. Smith et. al. noted the Median Co levels were 2.8 and $3.3 \mu \mathrm{g} / \mathrm{l}$ in the Durom and Birmingham groups, respectively, compared to only $0.52 \mu \mathrm{g} / \mathrm{l}$ in the Pinnacle group $(\mathrm{p}<0.001)$. They also noted that the median $\mathrm{Cr}$ levels were 2 and $2.2 \mu \mathrm{g} / \mathrm{l}$ in the Durom and Birmingham groups, respectively, compared to only $1.2 \mu \mathrm{g} / \mathrm{l}$ in the Pinnacle group $(\mathrm{p}<0.001)$. Only eight patients $(<3 \%)$ had confirmed cases of ALTR in our study. It is possible that implant specific screening may result in increased efficiency of identifying ALTR as well as decreasing the costs of screening. Matharu et. al. previously identified implant specific metal ion thresholds for detecting ALTR. This study evaluated the BHR and the Pinnacle modular two piece acetabular component [를. These implant specific cutoff values were then applied to an external cohort of patients and were once again noted to improve the detection of an ALTR [ $\underline{23}]$. However, there remains debate as to whether or not there are truly implant specific differences in metal ion levels [23]. Therefore, future screening protocols may place an emphasis on the frequency of screening based on risk stratification [24]. Future screening protocols might include implant design, abduction angle, head size, and symptoms.

It should be noted that screening tests in the medical field are regularly utilized in order to identify conditions with a high morbidity and or mortality such as cancer. Screening tests are commonly highly sensitive and will be associated with few false negative results. However, these 
tests may not necessarily be specific and often times require a confirmatory test to rule in or out the disease process. An example of this would be the prostate specific antigen (PSA) which is obtained to screen for prostate cancer. An elevated PSA $(>4.0 \mathrm{ng} / \mathrm{mL})$ will require a biopsy to confirm the diagnosis. Ideal screening tests are highly sensitive and have a low cost, and in the case of prostate cancer, the frequency and threshold of screening has been improved over time. Although an ALTR is not cancer, the associated morbidity can be devastating. For this reason, we still advocate screening asymptomatic patients with MoM THA. However, it is important to consider the costs of screening and potentially optimize the screening protocols to maximize sensitivity and decrease costs.

While the data was prospectively collected, the study design was retrospectively performed (retrospectively analyzing metal ions in a prospective cohort of MoM THA patients) and therefore has limitations. First, the screening protocol utilized in this study was not standardized. Serial clinical examinations, radiographs, and metal ion levels are now obtained every two years. During the majority of the study, routine screening protocols were not utilized. There is recent data that shows that serial metal ion levels may not be necessary in this asymptomatic patient population. Second, there are several limitations in the calculation of annual screening costs. It is possible that metal ion levels fluctuate day to day, or with activity, and therefore more frequent screening may increase the number of elevated metal ion levels obtained and potentially more ALTR identified. This has been simplified only to demonstrate the substantial cost differences noted when more frequent screening protocols are utilized. Third, metal ion labs have continued to decrease in costs. In 2014, cobalt and chromium ion levels cost approximately $\$ 300$, however current costs have dropped to $\$ 124$. Clearly, the cost-effectiveness will improve with decreasing costs of the test. Finally, the true incidence of ALTR is not known for the patient population in this study. Eight patients were revised with confirmed intraoperative ALTR identified. Only 12 patients underwent a MARS MRI and therefore 306 patients were not imaged. It is possible that a subset of these patients may have an ALTR with normal metal ion levels and therefore we note this as a limitation.

\section{Conclusion}

ALTR is a potentially devastating complication associated with MoM THA. Unfortunately, screening protocols are not uniform and rates of ALTR are low. The costs of screening asymptomatic patients in this study were
$\$ 612,250$. Due to the low incidence of ALTR in this patient population $(n=8)$, the cost of screening per ALTR was $\$ 76,531$. While more frequent screening may potentially increase the identification of ALTR, annual screening was associated with approximately a three-fold increase in the costs. Screening asymptomatic patients with MoM THA is necessary, but an emphasis should be placed on increasing the sensitivity of screening while decreasing the costs.

\section{Bibliography}

1. Chalmers BP, Perry KI, Taunton MJ, Mabry TM, Abdel MP. Diagnosis of adverse local tissue reactions following metal-on-metal hip arthroplasty. Curr Rev Musculoskelet Med. 2016;9(1):67-74. doi:10.1007/s12178-016-9321-3.

2. Mokka J, Junnila M, Seppänen $M$, et al. Adverse reaction to metal debris after ReCap-M2A-Magnum large-diameter-head metal-on-metal total hip arthroplasty. Acta Orthop. 2013;84(6):549-554. doi:10.3109/17453674.2013.859419.

3. Bernthal NM, Celestre PC, Stavrakis AI, Ludington JC, Oakes DA. Disappointing short-term results with the DePuy ASR XL metal-on-metal total hip arthroplasty. J Arthroplasty. 2012;27(4):539-544. doi:10.1016/j.arth.2011.08.022.

4. Matharu GS, Pandit HG, Murray DW. Poor Survivorship and Frequent Complications at a Median of 10 Years After Metal-on-Metal Hip Resurfacing Revision. Clin Orthop Relat Res. 2016;475(2):304-314. doi:10.1007/s11999-016-4882-4.

5. Plummer DR, Berger RA, Paprosky WG, Sporer SM, Jacobs JJ, Della Valle CJ. Diagnosis and Management of Adverse Local Tissue Reactions Secondary to Corrosion at the Head-Neck Junction in Patients With Metal on Polyethylene Bearings. J Arthroplasty. 2016;31(1):264-268. doi:10.1016/j.arth.2015.07.039.

6. Griffin WL. Metal ion levels: how can they help us? J Arthroplasty. 2014;29(4):659660. doi:10.1016/j.arth.2014.02.005.

7. Mistry A, Cahir J, Donell ST, Nolan J, Toms AP. MRI of asymptomatic patients with metal-on-metal and polyethylene-on-metal total hip arthroplasties. Clin Radiol. 2011;66(6):540-545. doi:10.1016/j.crad.2011.02.002.

8. Sutphen SA, MacLaughlin LH, Madsen AA, Russell JH, McShane MA. Prevalence of Pseudotumor in Patients After Metal-On-Metal Hip Arthroplasty Evaluated with Metal Ion Analysis and MARS-MRI. J Arthroplasty. 2016;31(1):260-263. doi:10.1016/j.arth.2015.07.011.

9. Garbuz DS, Hargreaves BA, Duncan CP, Masri BA, Wilson DR, Forster BB. The John Charnley Award: Diagnostic accuracy of MRI versus ultrasound for detecting pseudotumors in asymptomatic metal-on-metal THA. Clin Orthop Relat Res. 2014;472(2):417-423. doi:10.1007/s11999-013-3181-6.

10. Griffin WL, Fehring TK, Kudrna JC, et al. Are Metal Ion Levels a Useful Trigger for Surgical Intervention? J Arthroplasty. 2012;27(8):32-36. doi:10.1016/j. arth.2012.03.020.

11. Hart A., Sabah S., Sampson B, et al. Surveillance of Patients with Metal-on-Metal Hip Resurfacing and Total Hip Prostheses. J Bone Jt Surgery-American Vol. 2014;96(13):1091-1099. doi:10.2106/JBJS.M.00957.

12. Paustenbach DJ, Galbraith DA, Finley BL. Interpreting cobalt blood concentrations in hip implant patients. Clin Toxicol (Phila). 2014;52(2):98-112. doi:10.310 9/15563650.2013.857024.

13. Medical and Healthcare products Regulatory Agency (MHRA). Medical Device Alert: all metal-on-metal (MoM) hip replacements. MDA/2012/036. http://www. mhra.gov.uk/. Published 2012.

14. Kiran M, Shivarathre D, Peter VK. Blood Metal Ion Levels Have Limited Utility in the Surveillance of Asymptomatic Large-Head Metal-on-Metal Total Hip Arthroplasties. J Arthroplasty. July 2017. doi:10.1016/j.arth.2017.07.015.

15. Sidaginamale RP, Joyce TJ, Lord JK, et al. Blood metal ion testing is an effectivescreening tool to identify poorly performing metal-on-metal bearingsurfaces. Bone Joint Res. 2013;2(5):84-95. doi:10.1302/2046-3758.25.2000148.

16. Hjorth MH, Stilling M, Soballe K, et al. No association between pseudotumors, high serum metal-ion levels and metal hypersensitivity in large-head metal-on-metal total hip arthroplasty at 5-7-year follow-up. Skeletal Radiol. 2016;45(1):115125. doi: $10.1007 / \mathrm{s} 00256-015-2264-8$. 
17. Reito A, Parkkinen J, Puolakka T, Pajamäki J, Eskelinen A. Diagnostic utility of joint fluid metal ion measurement for histopathological findings in metal-on-metal hip replacements. BMC Musculoskelet Disord. 2015;16(1):393. doi:10.1186/ s12891-015-0851-4.

18. Renner L, Schmidt-Braekling T, Faschingbauer M, Boettner F. Do cobalt and chromium levels predict osteolysis in metal-on-metal total hip arthroplasty? Arch Orthop Trauma Surg. 2016;136(12):1657-1662. doi:10.1007/s00402-016-2565-y.

19. Fehring TK, Fehring K, Odum SM. Metal Artifact Reduction Sequence MRI Abnormalities Occur in Metal-on-polyethylene Hips. Clin Orthop Relat Res. 2015;473(2):574-580. doi:10.1007/s11999-014-3873-6.

20. Jennings JM, Martin JR, Kim RH, Yang CC, Miner TM, Dennis DA. Metal Artifact Reduction Sequence MRI Abnormalities in Asymptomatic Patients with a Ceramic-on-Polyethylene Total Hip Replacement. J Bone Jt Surg. 2017;99(7):593598. doi:10.2106/JBJS.16.00910.

21. Smith J, Lee D, Bali K, et al. Does bearing size influence metal ion levels in largehead metal-on-metal total hip arthroplasty? A comparison of three total hip systems. J Orthop Surg Res. 2014;9:3. doi:10.1186/1749-799X-9-3.

22. Matharu GS, Berryman F, Brash L, Pynsent PB, Treacy RBC, Dunlop DJ. The Effectiveness of Blood Metal Ions in Identifying Patients with Unilateral Birmingham Hip Resurfacing and Corail-Pinnacle Metal-on-Metal Hip Implants at Risk of Adverse Reactions to Metal Debris. J Bone Jt Surg. 2016;98(8):617-626. doi: 10.2106/JBJS.15.00340.

23. Matharu GS, Berryman F, Judge A, et al. Blood Metal Ion Thresholds to Identify Patients with Metal-on-Metal Hip Implants at Risk of Adverse Reactions to Metal Debris. J Bone Jt Surg. 2017;99(18):1532-1539. doi:10.2106/JBJS.16.01568.

24. Hothi HS, Eskelinen AP, Berber R, et al. Factors Associated With Trunnionosis in the Metal-on-Metal Pinnacle Hip. J Arthroplasty. 2017;32(1):286-290. doi:10.1016/j.arth.2016.06.038

\section{SUBMISSION HISTORY}

Submitted: October 24, 2018

Reviewed: December 10, 2018

Revised: December 16, 2018

Accepted: March 8, 2019

Published: March 31, 2019

\section{AUTHOR AFFILIATIONS}

1 J. Ryan Martin, MD; Bryan Springer, MD ; William Griffin, MD OrthoCarolina, Hip and Knee Center, 2001 Vail Avenue Suite 200A, Charlotte, NC 28207

2 Jesse Otero, MD, PhD

University of lowa Carver College of Medicine, 200 Hawkins Drive, Iowa City, IA 52242-1009

(Direct inquires to Ryan Martin, johrmart@gmail.com)

\section{AUTHOR DISCLOSURES}

The authors declare that there are no disclosures regarding the publication of this paper.

\section{COPYRIGHT \& OPEN ACCESS}

(C) 2019 Martin, Otero, Springer, Griffin. All rights reserved.

Authors retain copyright and grant the journal right of first publication with the work. Reconstructive Review is an open access publication and follows the Creative Commons Attribution-NonCommercial CC BY-NC. This license allows anyone to download works, build upon the material, and share them with others for non-commercial purposes as long as they credit the senior author, Reconstructive Review, and the Joint Implant Surgery \& Research Foundation (JISRF). An example credit would be: "Courtesy of (senior author's name), Reconstructive Review, JISRF, Chagrin Falls, Ohio".
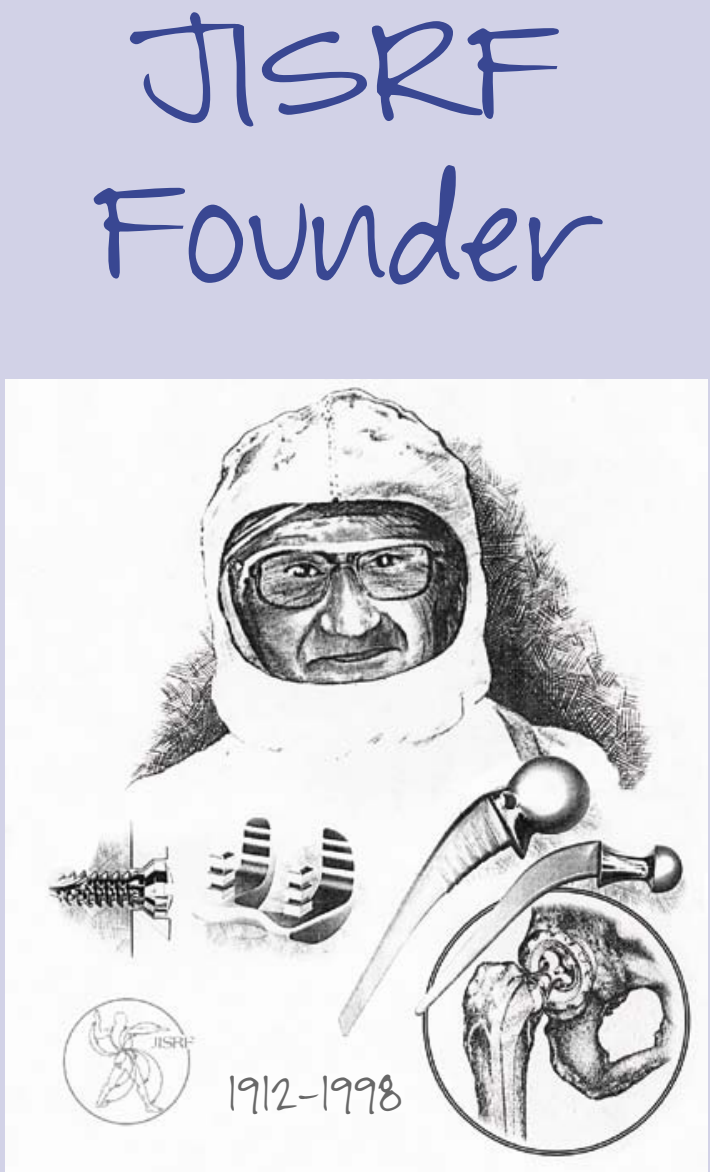

\section{Charles Bechtol, MD}

was internationally known in the fields of

biomechanics and orthopedic surgery. His

engineering and biomechanical research

resulted in the development of numerous joint

replacement implants and internal fracture

fixation devices - instruments that are familiar

to orthopedic surgeons the world over. His

innovations included shoulder and knee

prostheses, the Bechtol Total Hip system, the

Bechtol "fluted" bone screw, and the Bechtol

"continuous strength" bone plate.

Visit www.jisrf.org for more information. 